\title{
Anxio-Depressive Morbidity in Chronic Hemodialysis at the CHU SO of Lome (Togo)
}

\author{
Kokou Messanh Agbémélé Soedje ${ }^{*}$, Kossi Akomola Sabi², Eyram Yoan Makafui Amekoudi², \\ Kparakate Bouboune Kota-Mamah2, Befa Noto-Kadou-Kaza², Bartholome Komivi Azorbly', \\ Joel Mawuko Gbetogbe1, Kolou Simliwa Dassa1
}

${ }^{1}$ Clinic of Psychiatry and Medical Psychology, CHU-Campus, Lomé, Togo

${ }^{2}$ Department of Nephrology and Hemodialysis, Unit of CHU-Sylvanus Olympio, Lomé, Togo

Email: ${ }^{\star}$ soedjem@gmail.com

How to cite this paper: Soedje, K.M.A., Sabi, K.A., Amekoudi, E.Y.M., Kota-Mamah, K.B., Noto-Kadou-Kaza, B., Azorbly, B.K., Gbetogbe, J.M. and Dassa, K.S. (2017) Anxio-Depressive Morbidity in Chronic Hemodialysis at the CHU SO of Lome (Togo). Open Journal of Nephrology, 7, 2537.

https://doi.org/10.4236/ojneph.2017.72004

Received: March 21, 2017

Accepted: June 13, 2017

Published: June 16, 2017

Copyright (c) 2017 by authors and Scientific Research Publishing Inc. This work is licensed under the Creative Commons Attribution International License (CC BY 4.0).

http://creativecommons.org/licenses/by/4.0/ (c) (i) Open Access

\begin{abstract}
Introduction: This work aims to identify and analyze the anxio-depressive morbidity that the renal insufficiency in hemodialysis can present. Methodology: The framework of this work was the department of nephrology and the hemodialysis unit of the CHU Sylvanus Olympio of Lome. This was a crosssectional, single-pass, descriptive and analytical study that ran from January $1^{\text {st }}, 2016$ to June $30^{\text {th }}$, 2016. Included were all chronic hemodialysis patients who gave their free and well-informed consent and who have no psychiatric history. To assess anxiety and depression, the Hospital Anxiety and Depressive Scale of Zigmond and Snaith was used. The processing of the data was done with the software Epi Info 7 (version 7.1.2.0). Results: The number of patients was 91 and all were included. The mean age at $46.51 \pm 14.41$ years with extremes of 11 and 84 years and a sex ratio at 1.6 were observed. Anxiety (A3) was in $52.8 \%$ of women and depressed (D3) in $63.2 \%$ of men. The absence of social security increases the risk of anxiety disorders among respondents by three $(R R=2.6, p=0.04)$. A duration of change of Chronic Renal Failure (CRF) less than 6 months was associated with the occurrence of depression $(\mathrm{p}=0.04)$ with hemodialysis patients. The relative risk of depressive episodes increased three-fold with the hemodialysis patients $(R R=2.7)$. Conclusion: Collaboration between psychiatrists, psychologists and somaticians (doctors of the body) can occur at different times during dialysis, in order to overcome the difficulties that may arise during the treatment.
\end{abstract}

\section{Keywords}

Anxiety, Depression, Renal Dialysis, Psychopathology, Sub-Saharan Africa

\section{Introduction}

Chronic renal failure is a serious disease that causes a gradual and irreversible 
deterioration of the ability of the kidneys to filter blood and excrete certain hormones. The products of the metabolism and the excess water pass less and less in the urine and accumulate in the organism [1]. Hemodialysis is what is called a renal supplementation method, that is, a technique to survive with kidneys that no longer function or almost no longer function. It makes it possible to rid the blood of the waste and the water normally eliminated by the kidneys and thus realizes an extra-renal purification of the organism. Hemodialysis has transformed the evolutionary course, once fatal of chronic renal failure. It improved patient comfort and life expectancy [2].

The treatment of renal insufficiency by chronic hemodialysis is often associated with impaired quality of life of patients [3] [4]. Although the progression of diagnostic and therapeutic techniques has significantly improved the prognosis of many chronic patients, renal insufficiency presents a particular problem in that it is still waiting for a renal transplant since hemodialysis provides only its survival. During this period, the improvement of the patient's quality of life depends on taking care of his multiple health problems, which must in particular take account of the installation in the duration of the situation of substitution (the Hemodialysis) and the degree of tolerance of the patient [5]. These problems are often underestimated due to selective attention focused on kidney disease and/or diagnostic difficulty due to an entanglement of various disorders. These include anxiety and depression, linked to the disabling and often painful nature of the disease, but also to socio-economic handicaps [6] [7] [8] [9]. Anxiety and depressive disorders can have a considerable influence on the prognosis of this chronic pathology. The context is quite peculiar in tropical environment compared to representations and the experience of being connected to machines several times a week. In everyday practice, these problems are not at the forefront because of standardization or even a lack of knowledge of these disorders, of the importance often attributed to their organic appearance and difficulties in their evaluation. Few studies have investigated the magnitude of these mental health problems in hemodialysis and the factors associated with them in Togo. Most authors also point out that the prognosis of moderate anxiety and depressive disorders is not as favorable as is thought and that the cost of their management is often higher than that of severe psychiatric states [7] [10].

It is within the framework of a global approach of the patient in hemodialysis and to highlight these disorders that this work was initiated for a better management. It aims to identify and analyze the anxio-depressive morbidity that can present the renal insufficiency in hemodialysis.

\section{Methodology}

\subsection{Study Framework}

The study was carried out in the department of nephrology and hemodialysis unit of the CHU Sylvanus Olympio in Lomé, with a total capacity of 16 beds for 11 functional dialysis stations. This structure is the only state hemodialysis center in Togo. 


\subsection{Patients and Methods}

\subsubsection{Type, Period of Study and Patients}

This was a single-pass cross-sectional study with a descriptive and analytical purpose which took place from January $1^{\text {st }}, 2016$ to June $30^{\text {th }}, 2016$, so, duration of 6 months. The sample size was 91 .

All patients with chronic hemodialysis for at least one (1) month at the beginning of the study period and having given their free and well-informed consent have been included regardless of age, sex, race and nationality.

Patients with a proven history of psychiatric illness regardless of the diagnosis as well as those with a cognitive impairment were excluded.

\subsubsection{Data Collection}

A doctoral student has personally collected the data using a standardized survey form pre-established in semi-directed interview, with each patient seen after his dialysis session and by appointment and to whom the goal of this work has already been explained. This fact sheet included socio-demographic data (age, sex, marital status, level of education, profession, number of dependent children, relatives, existence of financial income), clinical data and management of renal insufficiency and data on the assessment of anxiety and depression.

To assess anxiety and depression, a psychometric scale was scored: the Hospital Anxiety and Depressive Scale of Zigmond and Snaith [11].

The Hospital Anxiety and Depressive Scale is a questionnaire consisting of 14 items: seven (7) items for the exploration of anxiety symptoms; Seven (7) items for the exploration of depressive symptoms. Each item is rated from 0 to 3 depending on the severity of the symptoms. It takes the total of the slope anxiety and depression: 21 points maximum for each. A score of less than 8 corresponds to an absence of anxiety (Group A1) and depression (Group D1), a score between 8 and 10 corresponds to a questionable anxious condition (Group A2) or doubtful depressive condition (Group D2), a score above 10 corresponds to a certain anxiety state (Group A3) or certain depression (Group D3).

The doctoral student in question had done a specific theoretical and practical training in nephrology and an apprenticeship of passing the test by a psychiatrist with whom he carried out a preliminary investigation. For patients who did not understand French, questions were translated as they were evaluated in the vernacular. The diagnoses used respected the diagnostic criteria of the International Classification of Diseases $10^{\text {th }}$ version (ICD 10) both for the renal insufficiency in its various stages and for the diagnosis of anxiety disorders or depressive states in their various clinical forms.

\subsubsection{Data Processing and Analysis}

For the analysis, the explanatory variables were age, sex, marital status, education level and mean duration of renal disease progression prior to hemodialysis, and the variables explained were life on hemodialysis; depression and anxiety. The processing of the data was done with the software Epi Info 7 (version 7.1.2.0). It included the calculation of averages, minimum, maximum and stan- 
dard deviation. The chi-square test, the Fischer tests, the Pearson and one-factor analysis were used. The significance level was set at $5 \%$.

\section{Results}

The number of patients treated with chronic hemodialysis in the nephrology department of the CHU-SO at the time of the study was 91 . All patients met the inclusion criteria and consented to participate in the study, participation rate of $100 \%$.

\subsection{Socio-Demographic Data}

The sample under study had an average age of 46.51 years with a standard deviation of 14.41 and extremes of 11 and 84 years. The age group from 40 to 59 was predominantly represented to $48.35 \%$, or 44 patients, followed by that of 20 to 39 years to $30.77 \%$, or $28 \%$ dialyzed. The male sex predominated with 56 patients $(61.54 \%)$ versus 35 women $(38.46 \%)$, a sex ratio of 1.6 . The majority of hemodialysis patients, $71.43 \%$ were in couples (65 patients married or in cohabitation). Of the $93.41 \%$ educated ( 85 respondents) in this series, $40 \%$ (46 respondents) had secondary education level and $32.97 \%$ (30 respondents). In the professional domain, executives, retirees, liberal professions and traders/distributors were respectively accounted for 26.37 percentage ( 24 hemodialysis), 15.38 (14 hemodialysis), 14.29 (13 hemodialysis) and 13.19 (12 hemodialysis). Workers, unemployed, housewives, soldiers and students constituted other professional profiles. Sixty-eight point thirteen percent or 62 patients lost their jobs with the disease. About health insurance, 60 hemodialysis (65.93\%) did not have insurance. Concerning the number of dependent children, 43 patients (47.25\%), 29 patients $(31.87 \%), 17$ patients $(18.68 \%)$ and 2 patients $(2.20 \%)$, had respectively 1 to 3 patients, 0,4 to 6 and over 7 dependent children. Relative to the way of life, $87.91 \%$ or 78 people lived in family. The attitude of the family was an acceptance and support to $80.22 \%$ ( 75 cases), an indifference to $13.19 \%$ (12 cases) and a rejection in $6.59 \%$ (6 cases).

\subsection{Clinical Data}

The duration of the Chronic Renal Failure (CRF) before hemodialysis was on average 9.16 months with extremes of 0 to 84 months. The average duration of life in hemodialysis was 44.44 months with extremes of 1 and 151 months.

The backgrounds were dominated by high blood pressure to $68.13 \%$ and the practice of self-medication was noted to $37.36 \%$. Initial nephropathy was essentially vascular in the sample to $48.35 \%$. The causes of nephropathy were mainly arterial high blood pressure up to $50.55 \%$. These results are highlighted in Table 1 .

\subsection{Demographic and Socio-Professional Parameters according to Anxiety and Depression Groups}

Anxiety (A3) was to $52.8 \%$ of women and depressed (D3) to $63.2 \%$ of men. Levels of secondary and university education were more strongly represented in the 
Table 1. Clinical and prevalence data for hemodialysis anxiety and depression.

\begin{tabular}{|c|c|c|}
\hline & Number $\mathrm{n}=91$ & Percentages $\%$ \\
\hline \multicolumn{3}{|l|}{ Pathological and dieatary history } \\
\hline High Blood Pressure & 62 & 68.13 \\
\hline Diabetes & 9 & 9.89 \\
\hline Renal disease & 6 & 6.59 \\
\hline Hemoglobinopathy AS & 3 & 3.30 \\
\hline Cardiopathy & 1 & 1.10 \\
\hline Hypercholesterolemia & 1 & 1.10 \\
\hline Surgery & 31 & 34.07 \\
\hline Self-medication & 34 & 37.36 \\
\hline Infusion & 29 & 31.87 \\
\hline Alcohol user & 7 & 7.69 \\
\hline Tobacco user & 5 & 5.49 \\
\hline Others* & 6 & 6.59 \\
\hline \multicolumn{3}{|l|}{ Initial nephropathy } \\
\hline Vascular & 44 & 48.35 \\
\hline Glomerular & 26 & 28.57 \\
\hline Interstitial tubulo & 12 & 13.19 \\
\hline Not determined & 7 & 7.69 \\
\hline Mixed & 2 & 2.20 \\
\hline \multicolumn{3}{|l|}{ Causes of nephropathy $\mu$} \\
\hline High Blood Pressure & 46 & 50.55 \\
\hline Toxic & 9 & 9.89 \\
\hline Diabetes & 9 & 9.89 \\
\hline Not determined & 7 & 7.69 \\
\hline Pregnancy & 6 & 6.59 \\
\hline Chronic Glomerular Nephropathy & 4 & 4.40 \\
\hline Infection with Human Immunodeficiency Virus & 4 & 4.40 \\
\hline Multiple myeloma & 2 & 2.20 \\
\hline Nephrotic syndrome & 2 & 2.20 \\
\hline Autosomal Dominant Polycystic Disease & 2 & 2.20 \\
\hline Lithiasis & 2 & 2.19 \\
\hline Lupus Erythematosus Disseminated & 1 & 1.10 \\
\hline Viral hepatitis B & 1 & 1.10 \\
\hline Sickle-cell anemia & 1 & 1.10 \\
\hline \multicolumn{3}{|l|}{ Prevalence of anxiety and depression } \\
\hline \multicolumn{3}{|l|}{ Anxiety } \\
\hline A3 (certain anxiety) & 36 & 39.56 \\
\hline A1 (No anxiety) & 29 & 31.87 \\
\hline A2 (doubtful anxiety) & 26 & 28.57 \\
\hline \multicolumn{3}{|l|}{ Depression } \\
\hline D3 (certain depression) & 38 & 41.76 \\
\hline D1 (No depression) & 34 & 37.36 \\
\hline D2 (doubtful depression) & 19 & 20.88 \\
\hline
\end{tabular}

*Valvulopathy, Vasculo-Cerebral Accident, Polyarthritis Rheumatoid, Cataract, Myeloma, Lupus Erythematosus Disseminated; $\mu$ Possibility of several etiologies that can explain the CRF. 
anxiety group, with rates of $50 \%$ and $27.8 \%$, respectively, than in the depressed group, with $47.4 \%$ and $34.2 \%$, respectively. Compared to those who lived together, $75 \%$ were anxious (A3) and $65.8 \%$ of the depressed (D3) were in a couple. The majority of hemodialysis patients without health insurance were in the anxiety group $(77.8 \%)$ and the depressed group $(73.7 \%)$. These results are explained in Table 2.

\subsection{Factors Associated with the Occurrence of Anxiety}

Female sex was associated with the occurrence of anxiety disorders $(p=0.03)$ with hemodialysis patients. The relative risk of anxiety was increased threefold in female dialysis patients $(\mathrm{RR}=2.6)$. The profession of trader/reseller was associated with the occurrence of anxiety disorders $(\mathrm{p}=0.04)$. The risk of developing anxiety with hemodialysis was multiplied by 4 with traders or resellers $(\mathrm{RR}=$ 3.6). The absence of social security increases the risk of anxiety disorders among respondents by three $(\mathrm{RR}=2.6, \mathrm{p}=0.04)$. Among the clinical factors studied, neither the existence of chronic disease nor the duration of renal disease progression and nor the duration of life by hemodialysis had any influence on the occurrence of anxiety ( $p>0.05$ ). Table 3 highlights the details of these assertions.

Table 2. Distribution according to demographic and socio-professional parameters.

\begin{tabular}{|c|c|c|c|c|c|c|}
\hline & \multicolumn{3}{|c|}{ Anxiety } & \multicolumn{3}{|c|}{ Depression } \\
\hline & A1 n(\%) & A2 $n(\%)$ & A3 n(\%) & D1 n(\%) & $\mathrm{D} 2 \mathrm{n}(\%)$ & D3 n(\%) \\
\hline Gender F & $9(31.0)$ & $8(30.8)$ & $19(52.8)$ & $13(38.2)$ & $9(47.4)$ & $14(36.8)$ \\
\hline Gender M & $20(69.0)$ & $18(69.2)$ & $17(47.2)$ & $21(61.8)$ & $10(52.6)$ & $24(63.2)$ \\
\hline \multicolumn{7}{|l|}{ Education } \\
\hline Uneducated & $1(03.5)$ & $2(07.7)$ & $3(08.3)$ & $1(02.9)$ & $3(15.8)$ & $2(05.3)$ \\
\hline Primary & $1(03.5)$ & $3(11.5)$ & $5(13.9)$ & $3(08.8)$ & $1(05.3)$ & $5(13.2)$ \\
\hline Secondary & $13(44.8)$ & $15(57.7)$ & $18(50.0)$ & $19(55.9)$ & $9(47.4)$ & $18(47.4)$ \\
\hline University & $14(48.2)$ & $6(23.1)$ & $10(27.8)$ & $11(32.4)$ & $6(31.6)$ & $13(34.2)$ \\
\hline \multicolumn{7}{|l|}{ Marital status } \\
\hline In pair & $22(75.9)$ & $16(61.5)$ & $27(75.0)$ & $23(67.7)$ & $17(89.5)$ & $25(65.8)$ \\
\hline Non in pair & $7(24.1)$ & $10(38.5)$ & $9(25.0)$ & $11(32.3)$ & $2(10.5)$ & $13(34.2)$ \\
\hline \multicolumn{7}{|l|}{ Social security } \\
\hline Insured & $17(58.6)$ & $7(26.9)$ & $8(22.2)$ & $15(44.1)$ & $7(36.8)$ & $10(26.3)$ \\
\hline Non insured & $12(41.4)$ & $19(73.1)$ & $28(77.8)$ & $19(55.9)$ & $12(63.2)$ & $28(73.7)$ \\
\hline \multicolumn{7}{|l|}{ Relatives } \\
\hline Living with family & $24(82.8)$ & $25(96.1)$ & $31(86.1)$ & $30(88.2)$ & $17(89.5)$ & $33(86.8)$ \\
\hline Living alone & $5(17.2)$ & $1(03.9)$ & $5(13.9)$ & $4(11.8)$ & $2(10.5)$ & $5(13.2)$ \\
\hline \multicolumn{7}{|l|}{ Employment } \\
\hline Stable employment & $15(51.7)$ & $4(15.4)$ & $10(27.8)$ & $16(47.1)$ & $5(26.3)$ & $8(21.0)$ \\
\hline Loss of employment & $14(48.3)$ & $22(84.6)$ & $26(72.2)$ & $18(52.9)$ & $14(73.7)$ & $30(79.0)$ \\
\hline
\end{tabular}


Table 3. Demographic, socio-professional and clinical factors crossed with anxiety.

\begin{tabular}{|c|c|c|c|c|}
\hline & \multicolumn{2}{|c|}{ Anxiety n(\%) } & \multirow[t]{2}{*}{$\mathrm{RR}^{1}\left[\mathrm{IC}_{95 \%}\right]^{2}$} & \multirow[t]{2}{*}{$\mathrm{p}^{3}$} \\
\hline & yes & no & & \\
\hline \multicolumn{5}{|c|}{ Demographic factors } \\
\hline Gender & & & & 0.03 \\
\hline Female & $19(52.8)$ & $17(47.2)$ & $2.6[1.0-5.9]$ & \\
\hline Male & $17(30.9)$ & $38(69.1)$ & & \\
\hline \multicolumn{5}{|l|}{ Age } \\
\hline$\geq 50$ years & $12(30.0)$ & $28(70.0)$ & $0.5[0.2-1.2]$ & 0.10 \\
\hline$<50$ years & $24(47.1)$ & $27(52.9)$ & & \\
\hline \multicolumn{5}{|l|}{ Marital status } \\
\hline In pair & $27(41.5)$ & $38(58.5)$ & $1.3[0.5-3.5]$ & 0.50 \\
\hline Non in pair & $9(34.6)$ & $17(65.4)$ & & \\
\hline \multicolumn{5}{|l|}{ Education } \\
\hline Uneducated & $3(50.0)$ & $3(50.0)$ & $1.6[0.3-8.3]$ & 0.60 \\
\hline Educated & $33(38.8)$ & $52(61.2)$ & & \\
\hline \multicolumn{5}{|c|}{ Socio-professional factors } \\
\hline \multicolumn{5}{|l|}{ Profession } \\
\hline Trader/Reseller & $8(66.7)$ & $4(33.3)$ & $3.6[1.0-13.2]$ & 0.04 \\
\hline Liberal & $7(53.9)$ & $6(46.1)$ & $2.0[0.6-6.40]$ & 0.30 \\
\hline Executive & $10(41.7)$ & $14(58.3)$ & $1.1[0.4-2.90]$ & 0.80 \\
\hline Worker & $3(37.5)$ & $5(62.5)$ & $0.9[0.2-4.10]$ & 0.90 \\
\hline Pensioner & $3(21.4)$ & $11(78.6)$ & $0.4[0.1-1.40]$ & 0.10 \\
\hline Housewife & $1(16.7)$ & $5(83.3)$ & $0.3[0.0-2.50]$ & 0.20 \\
\hline unemployed & $3(42.9)$ & $4(57.1)$ & $1.2[0.2-5.50]$ & 0.90 \\
\hline \multicolumn{5}{|l|}{ Stable employment } \\
\hline Yes & $10(34.5)$ & $19(65.5)$ & $0.7[0.3-1.80]$ & 0.50 \\
\hline No & $26(41.9)$ & $36(58.1)$ & & \\
\hline \multicolumn{5}{|l|}{ Social security } \\
\hline Insured & $8(25.8)$ & $23(74.2)$ & & \\
\hline Uninsured & $28(46.7)$ & $32(53.3)$ & $2.6[0.9-6.50]$ & 0.04 \\
\hline \multicolumn{5}{|l|}{ Financial aid } \\
\hline Yes & 19(35.9) & $34(64.1)$ & $0.7[0.3-1.60]$ & 0.40 \\
\hline No & $17(44.7)$ & $21(55.3)$ & & \\
\hline \multicolumn{5}{|l|}{ Dependent child } \\
\hline Yes & $24(38.7)$ & $38(61.3)$ & $0.9[0.4-2.20]$ & 0.80 \\
\hline No & $12(41.4)$ & $17(58.6)$ & & \\
\hline \multicolumn{5}{|l|}{ Relative } \\
\hline Living in family & $31(38.8)$ & $49(61.2)$ & $0.8[0.2-2.70]$ & 0.70 \\
\hline Living alone & $5(45.4)$ & $6(54.6)$ & & \\
\hline \multicolumn{5}{|l|}{ Clinical factors } \\
\hline Chronic disease & & & & \\
\hline
\end{tabular}


Continued

\begin{tabular}{ccccc}
\hline Yes & $25(34.7)$ & $47(64.3)$ & $0.5[0.2-1.3]$ & 0.2 \\
No & $10(52.6)$ & $9(47.4)$ & & \\
Duration of progression of CRI before dialysis & & & & \\
$<6$ months & $24(42.9)$ & $32(57.1)$ & $1.4[0.6-3.5]$ & 0.4 \\
$\geq 6$ months & $12(34.3)$ & $23(65.7)$ & & \\
Hemodialysis lifetime & & & & \\
$<6$ months & $8(44.4)$ & $10(55.6)$ & $1.3[0.5-3.6]$ & 0.6 \\
$\geq 6$ months & $28(38.4)$ & $45(61.6)$ & & \\
\hline
\end{tabular}

${ }^{1}:$ relative risk, ${ }^{2}$ : confidence interval, ${ }^{3}:$ chance.

\subsection{Factors Associated with the Onset of Depression}

No demographic factor influenced the onset of depression. The differences observed were random $(p>0.05)$. The socio-professional characteristics of the subjects did not significantly affect the occurrence of depression ( $p>0.05)$, although the loss of employment was associated with more depressive episodes $(\mathrm{p}=0.06)$. A period of evolution of the CRF under 6 months was associated with the occurrence of depression ( $\mathrm{p}=0.04)$ with hemodialysis patients. The relative risk of depressive episodes increased three-fold by these $(R R=2.7)$. These results are explained in Table 4.

\section{Discussion}

The study framework was the hemodialysis unit of the nephrology department of the CHU Sylvanus Olympio of Lome. It is the only public service for the diagnosis and management of nephrological diseases in Togo. Nevertheless, the small sample size (91 individuals) and its characteristics do not make it possible to generalize the results to the whole population. Data collection by one person limits the interpretation means of anxio-depressive symptoms. This experimental study on the psychiatric morbidity in hemodialysis in Togo has the merit of giving a scientific and real tendency of its diseases in the department of nephrology because having concerned the totality of the users.

The Hospital Anxiety and Depressive Scale (HADS) is a mixed questionnaire consisting of 14 items including 7 for anxiety and 7 for depression. The latter studies psychic phenomena as distinct categories. This categorical approach, which is very relevant in term of pedagogy, finds its limit in the existence of syndromic comorbidity (anxiety-depression).

\subsection{Epidemiological Aspects}

The mean age of hemodialysis patients was 46.5 years, with a greater representation of the $40-59$ age group at $48.35 \%$. There was also a male predominance of $61.54 \%$; or a sex-ratio of 1.6. The youth of the study population shows that renal insufficiency affects the economically active social strata. These results are similar to those of Maiga et al. [6] in Niamey (Niger) who found a mean age of 45.49 and a male predominance of $71.1 \%$. This male predominance was also noted by 
Table 4. Demographic, socio-professional and clinical factors influencing the occurrence of depression among respondents.

\begin{tabular}{|c|c|c|c|c|}
\hline & \multicolumn{2}{|c|}{ Depression n(\%) } & \multirow[t]{2}{*}{$\mathrm{RR}^{1}\left[\mathrm{IC}_{95 \%}\right]^{2}$} & \multirow[t]{2}{*}{$\mathrm{p}^{3}$} \\
\hline & yes & no & & \\
\hline \multicolumn{5}{|l|}{ Demographic factors } \\
\hline \multicolumn{5}{|l|}{ Gender } \\
\hline Female & $14(38.9)$ & $22(61.1)$ & $0.8[0.3-1.9]$ & 0.70 \\
\hline Male & $24(43.6)$ & $31(56.4)$ & & \\
\hline \multicolumn{5}{|l|}{ Age } \\
\hline$\geq 50$ years & $15(37.5)$ & $25(62.5)$ & $0.7[0.3-1.7]$ & 0.50 \\
\hline$<50$ years & $23(45.1)$ & $28(54.9)$ & & \\
\hline \multicolumn{5}{|l|}{ Marital status } \\
\hline In pair & $25(38.5)$ & $40(61.5)$ & $0.6[0.2-1.6]$ & 0.30 \\
\hline Non in pair & $13(50.0)$ & $13(50.0)$ & & \\
\hline \multicolumn{5}{|l|}{ Education } \\
\hline Uneducated & $36(42.3)$ & $49(57.7)$ & $1.5[0.3-8.5]$ & 0.70 \\
\hline Educated & $2(33.3)$ & $4(66.7)$ & & \\
\hline \multicolumn{5}{|c|}{ Socio-professional factors } \\
\hline \multicolumn{5}{|l|}{ Profession } \\
\hline Trader/Reseller & $5(41.7)$ & $7(58.3)$ & $0.9[0.3-3.40]$ & 0.90 \\
\hline Liberal & $7(53.9)$ & $6(46.1)$ & $1.8[0.5-5.80]$ & 0.30 \\
\hline Executive & $8(33.3)$ & $16(66.7)$ & $0.6[0.2-1.60]$ & 0.30 \\
\hline Worker & $5(62.5)$ & $3(37.5)$ & $2.5[0.6-11.3]$ & 0.20 \\
\hline Pensioner & $5(35.7)$ & $9(64.3)$ & $0.7[0.2-2.40]$ & 0.60 \\
\hline Housewife & $1((16.7)$ & $5(83.3)$ & $0.2[0.02-2.3]$ & 0.20 \\
\hline Unemployed & $5(71.4)$ & $2(28.6)$ & $3.9[0.7-21.0]$ & 0.09 \\
\hline \multicolumn{5}{|l|}{ Stable employment } \\
\hline Yes & $8(27.6)$ & $21(72.4)$ & $0.4[0.1-1.00]$ & 0.06 \\
\hline No & $30(48.4)$ & $32(51.6)$ & & \\
\hline \multicolumn{5}{|l|}{ Social security } \\
\hline Insured & $10(32.3)$ & $21(67.7)$ & $0.4[0.1-1.00]$ & 0.20 \\
\hline Uninsured & $28(46.7)$ & $32(53.3)$ & & \\
\hline \multicolumn{5}{|l|}{ Financial aid } \\
\hline yes & $26(49.1)$ & $27(50.9)$ & $2[0.8-4.90]$ & 0.09 \\
\hline No & $12(31.6)$ & $26(68.4)$ & & \\
\hline \multicolumn{5}{|l|}{ Dependent child } \\
\hline Yes & $22(35.5)$ & $40(64.5)$ & $0.4[0.2-1.10]$ & 0.07 \\
\hline No & $16(55.2)$ & $13(44.8)$ & & \\
\hline \multicolumn{5}{|l|}{ Relative } \\
\hline Living in family & $33(41.2)$ & $47(58.8)$ & $0.8[0.2-3.00]$ & 0.07 \\
\hline Living alone & $5(45.4)$ & $6(54.6)$ & & \\
\hline Clinical factors & & & & \\
\hline
\end{tabular}


Continued

\begin{tabular}{ccccc}
\hline $\begin{array}{c}\text { Chronic disease } \\
\text { Yes }\end{array}$ & $31(43.1)$ & $41(56.9)$ & $1.3[0.5-3.7]$ & 0.60 \\
No & $7(36.8)$ & $12(63.2)$ & & \\
Duration of progression of CRI before dialysis & & & & \\
$<6$ months & & & & \\
$\geq 6$ months & $28(50.0)$ & $28(50.0)$ & $2.7[1.0-6.2]$ & 0.04 \\
Hemodialysis lifetime & $10(28.6)$ & $25(71.4)$ & & \\
$<6$ months & & & & \\
$\geq 6$ months & $9(50.0)$ & $9(50.0)$ & $1.5[0.5-4.2]$ & 0.40 \\
\hline
\end{tabular}

${ }^{1}$ : relative risk, ${ }^{2}$ : confidence interval, ${ }^{3}$ : chance.

Njah et al. [5] to $57.79 \%$ in Monastir (Tunisia). In a study carried out in France in 2009, Untas et al. [12] had found a higher mean age at 63.1 years. Indeed, a higher life expectancy, supported by greater accessibility to quality health care and better socio-economic conditions in the West, may explain this difference.

This series recorded a high literacy rate at $93.41 \%$; which was not the case for Maiga et al. [6] where only $51.3 \%$ were literate. The occupational profile of this latter study was carried out on a population mainly based on trade and breeding (Niger), sectors of activity that do not necessarily require education. Moreover, the relatively low literacy rate of Niger, which is $28.7 \%$ against $60.4 \%$ in Togo, confirms this difference [13].

The mean duration of the CRF of patients before dialysis was 9.16 months. It is 4.6 years or 55.2 months in the Monastir series [5] and 33.85 months in the Niger series [6]. The very low mean among the respondents reflects the delay in the diagnosis and the specialized care of renal disease in this study, resulting in a rapid evolution towards a terminal CRF and therefore to a supply post treatment. The study recorded a mean duration of life in hemodialysis of 44.4 months or 3.7 years; which is similar to the result of Ndiaye-Ndongo et al. [2] in Senegal, which had recovered an average of 3.86 years or 46.32 months. These results contrast with those of Untas et al. [12] who had recorded oldness mean of 8 years' dialysis with a standard deviation of 6.4 years. The largest average dialysis life of the French series is explained not only by the higher life expectancy of the West, but also by other parameters such as delayed diagnosis, delayed treatment under replacement therapy due to its relatively high cost and no subsidy, and the inadequacy of hemodialysis center in developing countries. This is compounded by the fact that some patients undertook their first dialysis sessions in private centers, which would not have been taken into account in studies targeting national centers.

\subsection{Prevalence of Anxiety and Depressive Disorders}

Among the respondents, $41.76 \%$ had a definite depression (group D3) compared with $39.56 \%$ of definite anxiety (group A3). However, this difference is not significant $(\mathrm{p}>0.05)$. In a Tunisian series, $44 \%$ of depressive symptoms were re- 
corded with or without anxiety [5]. This rate was similar to that of this work even if the scales used were different. Moreover, this rate in its series takes into account both cases of probable anxio-depressive disorders and some cases. A study comparable to the present survey carried out in Niger [6] using the same rating scale (HADS) found that there was less definite depression at $23.7 \%$, and very few subjects definitely anxious at $14.5 \%$ [6]. Unlike the study sample, the dialysis patients in this series got a systematic psychological accompaniment, which may explain these observed differences.

\subsection{Factors Associated with Anxiety Disorders}

The women in this study expressed three times more anxiety than men $(\mathrm{RR}=$ $2.6, \mathrm{p}=0.03$ ). A study on anxiety and depression in hemodialysis carried out in France revealed the same finding $(\mathrm{RR}=2.6)[12]$. Women express more anxiety than men. This result is in line with the literature, where studies show that women are more anxious than men regardless of the measurement tools used [14]. In addition, the profession of trader or reseller who was four times more likely to develop anxiety disorders $(R R=3.6, p=0.04)$, was predominantly female at $83.3 \%$.

The prevalence of anxiety disorders did not show a significant effect of sex according to Maiga et al. [6] in Niger. Indeed, in this series, women were mainly housewives, thus without financial income; while in our study, most women or $77.8 \%$ had a job, therefore a financial income. The loss of this source of income with chronic renal disease would increase the occurrence of anxiety disorders. The professional activity is also considered as a protective factor while inactivity is often perceived as a source of social demoralization. The work would allow the patient to broaden the scope of his relationships, assume his responsibilities, assert his independence and thus control his situation [15] [16] [17].

Traders and resellers were the occupational group most affected by anxiety in this series, with a risk multiplied by four $(\mathrm{RR}=3.6, \mathrm{p}=0.04)$. This is due to the relative sedentariness imposed by dialysis when it is known that traders often travel to store supplies or deliver their items. Moreover, the uniqueness of the national dialysis center in Togo constitutes an obstacle to this need for migration, which is implied by trade. The absence of health insurance exposed dialysis patients to three times more risk of anxiety $(R R=2.6, p=0.04)$. Social security is an important relief especially in our context of low socio-economic level and especially since the costs of hemodialysis are not borne by the State.

\subsection{Factors Associated with Depression}

A progression of chronic renal disease of less than 6 months was associated with three times more risk of developing depression $(R R=2.7, p=0.04)$. It should be noted that similar studies, notably those of Niger [6], Tunisia [5] and France [12], did not find any change in psychiatric morbidity with regard to the duration of development of renal disease. In these series, the mean durations of progression of CRF was significantly higher than the present study, thus the patients 
would have had time to prepare psychologically for the possible reception of the status of chronic dialysis and also the presence in these studies of psychotherapeutic accompaniment. The shortness of the evolution of the disease due to late diagnosis and specialized care noted in this work could also be at the origin of this divergence. The loss of employment was associated with more depression in this study although not significant $(\mathrm{p}=0.06)$. The finding was the same for Njah M. et al. in Tunisia in 2001 [5]. Indeed, in the Tunisian series, the maintenance of the profession had even proved to be a protective factor with regard to depression. The fact that this event was not significant in this study would be due to the small sample size.

\section{Conclusion}

This work shows that anxiety and depressive disorders exist in patients in chronic hemodialysis in Lome, and that they affect more women, traders or retailers and individuals lacking social security. Depression more than anxiety is mainly due to a late diagnosis of chronic renal disease and the consequence is the early setting under iterative renal urea. In this context, the management of the patient in hemodialysis is multidisciplinary. Collaboration between psychiatrists, psychologists and somaticians (others doctors dealing with the psychic) may occur at different times during dialysis, in order to overcome the difficulties that may arise during treatment. Others non-significant factors, such as the inadequate hemodialysis center and the relatively high cost of dialysis sessions increase anxiety-depressive morbidity of patients. They can be a source of problems for both patient and healthcare team.

\section{Conflict of Interest}

None.

\section{References}

[1] Canadian Medical Association (Ed). General Public, Diseases-Chronic Renal Failure.

[2] Ndiaye-Ndongo, N., Samba, O., Sylla, A., Thiam, M. and Diouf, B. (2015) Depression in Chronic Hemodialysis. Med Afr Noir, 62, 603-608.

[3] Cissé, M., Ka, E., Gueye, A., Tall, M., Niang, A. and Diouf, B. (2012) Quality of Life for Hemodialysis Patients in Dakar Tropical Environment. Medicine and Tropical Health, 165, 198-202.

[4] Seica, A., Segall, L., Verzan, C., Vaduva, N., Madincea, M., Rusoiu, S., et al. (2009) Factors Affecting the Quality of Life of Haemodialysis Patients from Romania: A Multicentric Study. Nephrology Dialysis Transplantation, 24, 626-629. https://doi.org/10.1093/ndt/gfn506

[5] Njah, M., Nasr, M. and Ben Dhia, N. (2001) Anxio-Depressive Morbidity in Hemodialysis Patients. Nephrology, 22, 353-357.

[6] Maiga, D., Ide, A., Larabou, H., Seyni, H. and Sidikou, A. (2013) Depression and Anxiety in Patients with Chronic Hemodialysis at the Lamordé National Hospital (Niger): Prevalence and Time of Life during Hemodialysis. Perspective Psy, 52, 365-369.

[7] Consoli, S. (1990) Psychiatric Disorders of Chronic Renal Failure. Practical Review, 40, 640-643. 
[8] Olie, J., Poirier, M. and Loo, H. (1995) Depressive Illnesses. Edition Medicine-Sciences. Flammarion, Paris.

[9] Villeneuve, A., Cazejust, T. and Kammer, F. (1980) Depressive Affects in Organic Diseases. Medical Review, 2, 90-102.

[10] Faelli, S. (1979) Psychological Problems of Dialysed Patients. Acta Psychiatrica Belgica, 79, 535-536.

[11] http://www.has-sante.fr/portail/upload/docs/application/pdf/2014-11/outil_echelle_ had.pdf

[12] Untas, A., Aguirrezabal, M., Chauveau, P., Leguen, E., Combe, C. and Rascle, N. (2009) Anxiety and Depression in Hemodialysis: Validation of the Hospital Anxiety and Depression Scale (HADS). Nephrology and Therapeutics, 5, 193-200. https://doi.org/10.1016/j.nephro.2009.01.007

[13] Country Comparison: Literacy Rate. (2015) http://www.indexmundi.com/g/r.aspx?v=39\&l=en

[14] Egloff, B. and Schmukle, S. (2004) Gender Differences in Implicit and Explicit Anxiety Measures. Personality and Individual Differences, 36, 1807-1816. https://doi.org/10.1016/j.paid.2003.07.002

[15] Brour, S., Bahri, N. and Boussetta, A. (1991) Professional Disability and Psychiatry. Tunis Med, 69, 45-49.

[16] Chanoit, P. and Nasr, M. (1991) Epidemiology and the Prevention of Mental Illness. Medico-Psychological Annals, 145-149.

[17] Kovess, V. (1996) Epidemiology and Mental Health. Editions Médecine-Sciences, Flammarion, Paris.

\section{Notes of Translator}

ICD: International Classification of Diseases

CRF: Chronic Renal Failure

Submit or recommend next manuscript to SCIRP and we will provide best service for you:

Accepting pre-submission inquiries through Email, Facebook, LinkedIn, Twitter, etc. A wide selection of journals (inclusive of 9 subjects, more than 200 journals)

Providing 24-hour high-quality service

User-friendly online submission system

Fair and swift peer-review system

Efficient typesetting and proofreading procedure

Display of the result of downloads and visits, as well as the number of cited articles

Maximum dissemination of your research work

Submit your manuscript at: http://papersubmission.scirp.org/

Or contact ojneph@scirp.org 